Derecho y Realidad

Vol.13 -Núm. 26 • Julio-Diciembre de 2015

Pázs.121-152 • ISSN:1692-3936

\title{
Acuerdos de paz y finalización histórica del conflicto armado*
}

\author{
Peace agreements and historical end \\ of the armed conflict
}

\author{
Álvaro Villarraga Sarmiento**
}

\section{Resumen}

Colombia ha tenido siete décadas de conflicto bélico y de violencia sociopolítica. Entre 1946-1957 sucedió la confrontación partidista conservadora-liberal que cesó con un pacto de paz, un plebiscito y el régimen del Frente Nacional. Sobrevino la confrontación entre el Estado y las guerrillas de izquierda que se prolonga hasta la actualidad. La Asamblea Nacional Constituyente y la expedición de la Constitución Política de 1991 permitieron consolidar pactos de paz con las guerrillas M19, EPL y varias fracciones regionales. Ahora se registra un proceso de acuerdos muy avanzado entre el Gobierno Santos y las FARC-EP, la guerrilla más histórica y de mayor presencia y potencial militar. Simultáneamente, avanza la preparación de

Fecha de aceptación: 3 de septiembre de 2015

Concepto de recepción: 27 de septiembre de 2015

Fecha de aprobación: 11 de octubre de 2015

* Este artículo hace parte de una línea de investigación de la Fundación Cultura Democrática en el tema de Construcción de paz y procesos de resolución política del conflicto armado en Colombia, la cual es desarrollada por el equipo de trabajo del Proyecto Biblioteca de la Paz.

** Directivo del Centro Nacional de Memoria Histórica, fundador de la Fundación Cultura Democrática, catedrático universitario. 
una negociación similar Gobierno-ELN, la guerrilla que resta. De consolidarse estos pactos de paz, cesaría la guerra irregular interna y se daría la oportunidad para una transición con las reformas y medidas que sustenten una paz sostenible.

\section{Palabras clave}

Conflicto armado, paz, FARC, ELN, solución política, resolución de conflictos, refrendación ciudadana.

\section{Abstract}

Colombia has had seven decades of conflict and socio-political violence. During 1946-1957 occurred the confrontation between Liberal and Conservative parties that ended with a pact of peace, a plebiscite and the regime of the National Front. Then the confrontation between the State and left-wing guerrillas comes that lasts to the present day. The National Constituent Assembly and the issue of the Political Constitution of 1991 allowed the consolidation of peace pacts with M19, ELN guerrillas and several regional fractions. Now is undergoing a very advanced process of agreements between Santos Government and FARC-EP, the more historical guerrillas and with the highest presence and military potential. At the same time advances the preparation of a similar negotiation Government-ELN, the latter the remaining guerrilla. If these peace pacts consolidate, the internal irregular war would cease and the opportunity for a transition with reforms and measures that support a sustainable peace could be attained.

\section{Keywords}

Armed conflict, peace, FARC, ELNA, political solution, conflict resolution, citizen countersignature. 


\section{Sumario}

Introducción

1. Cronología de los acuerdos conseguidos con las FARC

2. Contenido de los acuerdos parciales Gobierno-FARC

3. Cuestionamientos e imprecisiones frecuentes sobre el proceso de paz

4. Oposición intransigente y uso de falacias contra el proceso de paz

5. El proceso en 2015: avances, crisis y notable recuperación

6. Acuerdo en justicia: debate necesario e inoportuno litigio entre las partes

7. El tema que resta: fin del conflicto

8. El debate sobre el mecanismo de refrendación ciudadana

9. La iniciativa gubernamental de Comisión Especial Legislativa

10. La demorada fase de exploración con el ELN

11. Conclusión

\section{Método}

Socio-histórico.

\section{Metodología}

Lo que pretende este trabajo es resaltar la importancia de los acuerdos de paz que se dieron en la habban entre gobierno y FARC, así como ver los intentos fallidos de este acuerdo 


\section{Introducción}

De culminar con éxito los procesos de paz actuales entre el Gobierno nacional y las guerrillas FARC y ELN y si se supera el fenómeno paramilitar, se cerraría en el país el ciclo de guerra irregular interna vivido por más de cinco décadas. Seguiría una fase de transición para aplicar los acuerdos de paz conseguidos, lograr la recuperación efectiva de los derechos humanos y garantizar una serie de reformas, medidas y programas orientados a superar las problemáticas de inequidad, exclusión social, altos márgenes de pobreza y ausencia de garantías para la oposición política, que han estado en la base del conflicto. Cobra por tanto importancia revisar los antecedentes, las dinámicas y las perspectivas que ofrecen los procesos de paz en curso.

Colombia registra 70 años (1946-2016) de existencia ininterrumpida de expresiones de conflicto bélico y de violencia generalizada, con distintos niveles de impacto, pero de forma que se han conjugado con dinámicas y acuerdos hacia el logro de la paz. Primero fue la confrontación producto de gobiernos autoritarios del Partido Conservador a partir de 1946, que utilizaron la Policía para promover grupos de civiles armados y atacar sistemáticamente a la población campesina liberal. La respuesta fue un alzamiento armado que se generalizó a través de guerrillas liberales $y$, en menor grado, guerrillas comunistas e independientes, que enfrentaron a la Fuerza Pública. Hecho que se conjugó con una ola de violencia social generalizada, motivada por retaliaciones y venganzas, entre pobladores afines al conservatismo o al liberalismo.

El cierre de esta confrontación coincide con su punto de mayor intensidad en 1953. Las dirigencias de los dos partidos enfrentados aceptaron un gobierno militar del general Gustavo Rojas, que haría una transición hacia la paz, parcialmente conseguida. Pero este gobierno militar derivó en una especie de dictadura, de forma que los partidos Liberal y Conservador, que aún se confrontaban en varias regiones, suscribieron en 1957 un pacto de paz $^{1}$, derrocaron con un paro cívico nacional al Gobierno, consiguieron amplio respaldo en un plebiscito del cual surgió el régimen del Frente Nacional, que les otorgó de manera exclusiva el ejercicio de la política y el acceso al poder público por 16 años. Se superó así esa fase de guerra civil, pero pervivieron grupos guerrilleros no amnistiados, autodefensas campesinas de orientación comunista y una ola de bandolerismo utilizada por poderes regionales que emergieron mediante el aprovechamiento de la violencia.

\footnotetext{
En las poblaciones españolas de Sitges y Benidorm, en 1957, firmó los acuerdos por el Partido Conservador el expresidente Laureano Gómez, y por el Partido Liberal, Alberto Lleras Restrepo, quien sería el inmediato presidente.
} 
Sobrevino desde 1964 otra guerra irregular, ahora entre el Estado y las guerrillas de izquierda, a partir del ataque militar del Gobierno conservador de Guillermo León Valencia contra las autodefensas campesinas del sur del país, hecho que dio origen a las FARC. De manera secuencial, el mismo año surgió el ELN como fusión de la anterior guerrilla liberal en el Magdalena Medio, con líderes estudiantiles simpatizantes de la Revolución cubana y algunos religiosos de la teología de la liberación -liderados por Camilo Torres Restrepo-. En 1967 irrumpió el EPL entre Antioquia y la región Caribe, a partir de levantamientos campesinos locales de anteriores guerrilleros liberales, unidos a este nuevo proyecto insurgente, que era liderado por una fracción del Partido Comunista y la JUCO, que optó por la vía revolucionaria.

Y en 1970 apareció el M19 en Bogotá, en reacción al fraude en las elecciones presidenciales de 1970 contra la ANAPO y con la vinculación de cuadros de las FARC de formación universitaria, que pretendían forjar una guerrilla urbana con alto impacto propagandístico, pero que luego para persistir en medio de la represión oficial, tuvo que proyectarse como guerrilla rural hacia el sur y occidente del país. En medio de la confrontación bélica, a partir de 1980 se generalizó por iniciativa oficial e impulso desde las brigadas militares la estrategia paramilitar, que también se articuló al narcotráfico y adquirió a la vez matices regionales propios, en medio de masacres y múltiples ataques contra la población considerada simpatizante de las guerrillas.

Este nuevo ciclo de guerra civil registra dos momentos de cierre. El primero, con un antecedente en las treguas de 1984-1987 (Gobierno Betancur con las FARC, el EPL y el M19) y con desenlace entre 1989 y 1991, en el contexto de la convocatoria y realización de la Asamblea Nacional Constituyente de 1991, que dio lugar a los pactos de paz definitivos con el M19, el EPL y varias milicias campesinas (PRT), urbanas de Medellín (MP) e indígenas en Cauca (MAQL). Estos sectores de la insurgencia incidieron en la expedición de la Constitución Política de 1991, la cual significó una apertura democrática, y nutrieron vertientes de la izquierda democrática y del movimiento indígena. Sus excombatientes retornaron a la vida civil.

Producto del influjo de estos procesos de paz, un sector minoritario del ELN (CRS) pactó la paz en 1994. Simultáneamente también lo hicieron las Milicias Populares de Medellín. Entre tanto, las FARC y el ELN prolongaron el alzamiento hasta la actualidad. A la vez, en los años 90 se expandió el fenómeno paramilitar bajo la sigla de las AUC, ocasionando miles de víctimas entre la población campesina señalada de tener relación con las guerrillas y de las organizaciones sociales y políticas de izquierda.

No obstante las dinámicas de confrontación armada, las FARC y el ELN sostuvieron diálogos de paz con varios gobiernos, sin llegar a resultados definitivos. Situación que arrojó experiencias positivas de aproximación, agendas, soluciones humanitarias 
e incidencia favorable a la paz de movimientos sociales y apoyo de la comunidad internacional, pero así mismo, el fracaso frente al logro de la paz despertó frustración y alentó, entre 2002 y 2010, gobiernos empeñados en el aniquilamiento de las guerrillas. Sin embargo, con realismo político, el presidente Juan Manuel Santos, aunque mantuvo la ofensiva militar, reconoció que persistir en el intento de aniquilar militarmente las guerrillas podría demorar otras décadas el conflicto con altos costos humanitarios y de todo orden. Por su parte, las FARC flexibilizaron posiciones para posibilitar el entendimiento.

EI presidente Santos inició conversaciones y acuerdos con las FARC y desde 2014 con el ELN, de manera que en la actualidad se registran avances notorios y decisivos con la primera guerrilla y aún exploratorios con la segunda. De tal manera que de conseguirse estos pactos de paz, acabaría la guerra irregular de cinco décadas entre el Estado y las insurgencias de izquierda, pero también podrían finalizar las expresiones de guerra civil y violencia sociopolítica generalizada, registradas por siete décadas. Este documento se orienta en consecuencia a entregar el análisis del importante avance en las conversaciones Gobierno-FARC y de la exploración inicial GobiernoELN, dejando en claro que si se logran con éxito estos nuevos pactos de paz y, más aun, si consiguen una favorable refrendación ciudadana, se darían las condiciones en el país para el cierre definitivo del conflicto bélico y, ojalá simultáneamente, de todas las formas de violencia sociopolítica que nos afectan.

\section{Cronología de los acuerdos conseguidos con las FARC}

El proceso de paz Gobierno-FARC inició con una fase exploratoria discreta en febrero de 2012. En agosto siguiente consiguió el "Acuerdo para la finalización del conflicto y el logro de una paz sostenible" con la agenda y las reglas de juego. En octubre instaló la mesa de conversaciones en Oslo, Noruega, y en noviembre inició las sesiones de negociación con sede en La Habana, Cuba. En mayo de 2013, la mesa hizo público el acuerdo "Desarrollo agrario integral"; en noviembre siguiente, el acuerdo sobre "Participación política y social"; Y en mayo de 2014, el acuerdo sobre superación de "Cultivos ilícitos". En junio de ese año creó la Subcomisión Técnica Fin del Conflicto y la Subcomisión de Género. En agosto se instaló la Comisión Histórica del Conflicto y las Víctimas, y se iniciaron las visitas a la mesa de delegaciones de diversas víctimas ocasionadas en el contexto del conflicto armado.

En noviembre de 2014, el presidente Santos suspendió las conversaciones ante la retención por las FARC del general Rubén Darío Alzate, cuando este hizo presencia sin dispositivo militar de protección en una zona de reconocida presencia de esta guerrilla en Chocó. La situación motivó un acuerdo especial humanitario, intermediado por el CICR. Reanudadas las negociaciones, el siguiente 20 de diciembre las FARC 
declararon por primera vez un cese al fuego unilateral e indefinido. Este mismo mes concluyeron las visitas de las delegaciones de víctimas a la mesa en La Habana.

En marzo de 2015, la mesa llegó a un acuerdo de desminado humanitario de aplicación inmediata, con acompañamiento de Noruega. En abril siguiente, las FARC, tras declarar que sufrían hostigamientos del Ejército, rompieron la tregua declarada con un fuerte ataque al Ejército en Cauca. En respuesta, las Fuerzas Militares realizaron cruentos bombardeos contra campamentos de las FARC. En junio de ese año, la mesa logró el acuerdo sobre la Comisión de la Verdad, la Convivencia y la No Repetición. El siguiente julio, en respuesta a la petición de los países garantes (Cuba y Noruega) y acompañantes (Venezuela y Chile), las partes convinieron agilizar las conversaciones y adoptar el desescalamiento militar.

En agosto de ese año, la mesa conformó una Comisión Jurídica conformada por asesores de ambas partes, la cual contribuyó al acuerdo sobre Jurisdicción Especial de $\mathrm{Paz}$, presentado en sus rasgos principales en el siguiente mes de septiembre. Simultáneamente, se reunieron el presidente Santos y el comandante de las FARC, "Timochenko", y convinieron concluir los acuerdos el 23 de marzo de 2016, de manera que en los 60 días siguientes se hará la dejación de las armas por parte de esta guerrilla. Ante el cumplimiento del cese al fuego por las FARC, el Gobierno mantuvo la orden de cesar los bombardeos contra campamentos guerrilleros y en noviembre concedió indulto a 30 prisioneros de las FARC por razones humanitarias y como gesto de entendimiento. El 15 de diciembre de 2015, las partes hicieron oficial la finalización del punto de víctimas, que incluyó varios acuerdos parciales sobre reconocimiento a las víctimas y sus derechos, esclarecimiento y memoria histórica, reparación de víctimas, Jurisdicción Especial de Paz y garantías de no repetición (pág. web avancesacuerdos.gov.co) (pág. web altocomisionadoparalapaz.gov.co ).

\section{Contenido de los acuerdos parciales Gobierno-FARC}

\section{Desarrollo rural integral}

Constitución de un fondo de tierras que incluya tierras incautadas o desaprovechadas para entregarlas a campesinos. Plan masivo de formalización de la propiedad y actualización del catastro rural. Promoción de planes de desarrollo con enfoque territorial, construcción de infraestructura, desarrollo social y estímulo a la productividad campesina. Adopción de una política de seguridad alimentaria y fortalecimiento de los mercados regionales. Pendientes: en reforma agraria con relación al latifundio, acordar delimitación de la propiedad; extranjerización del territorio; regulación de extracción minero-energética y de agrocombustibles; renegociación de los tratados de libre comercio; planes de ordenamiento territorial, uso del suelo y derecho real de superficie; creación del Consejo Nacional de la Tierra. 


\section{Participación política}

Apertura democrática, garantía a nuevas expresiones políticas. Circunscripciones especiales de paz para participación política de habitantes de regiones afectadas por el conflicto. Ley de garantías y estatuto de oposición. Promoción de una cultura de participación política con acceso a medios de comunicación institucionales y garantías a los medios regionales y comunitarios. Creación de un Sistema Integral de Seguridad para el ejercicio de la política. Pendientes: reestructuración del Estado y reforma política; reforma del sistema político electoral; reforma de los mecanismos de participación ciudadana; proscripción del tratamiento militar a la protesta social; elección popular del procurador, contralor, fiscal general y defensor del pueblo; participación ciudadana en la definición de políticas de interés nacional; democratización del acceso al espacio radioeléctrico y medidas frente a la monopolización de los medios masivos de comunicación.

\section{Drogas ilícitas}

Crear un programa de sustitución de cultivos de uso ilícito, un amplio plan de sustitución con participación de las comunidades desde su planeación. Plan de desminado del territorio nacional. Tratamiento al consumo de estupefacientes como problema de salud pública. Ampliación de la lucha contra el crimen organizado y los eslabones más altos de la cadena del narcotráfico y el lavado de activos. Pendientes: la propuesta de una nueva política criminal contra las drogas de uso ilícito; suspender las aspersiones de glifosato y reparar a las víctimas de esta práctica; la reforma del sistema de salud pública hacia la prevención y el consumo, y la realización de una conferencia nacional sobre la política en el tema.

\section{Víctimas}

Crear un sistema integral de verdad, justicia, reparación a las víctimas y garantías de no repetición. Principios sobre reconocimiento de las víctimas, compromiso con sus derechos y no impunidad. Creación y realización de los trabajos de la Comisión Histórica del Conflicto y las Víctimas sobre origen, dinámicas e impactos del conflicto y victimizaciones ocasionadas por los distintos actores. Conformación de una Comisión de la Verdad, la Convivencia y la No Repetición, con mandato a tres años para realizar un informe apoyado en audiencias públicas. Creación de la Circunscripción Especial de Paz que incluye un Tribunal Especial y salas para el tratamiento de amnistías e indultos a exguerrilleros y otras para el tratamiento de todos los actores comprometidos directamente con graves violaciones, bajo el enfoque de justicia restaurativa y con penas alternativas relacionadas con compromisos a la verdad, la reparación de las víctimas y la restricción de la libertad. Conformación de una Comisión de Búsqueda de las víctimas de desaparición forzada. Compromisos con la reparación 
de las víctimas desde todos los actores del conflicto responsables (pág. web avancesacuerdos.gov.co).

Este acuerdo, difícil de lograr por las implicaciones en justicia referidas, aunque se extendió su logro por más tiempo que los antes referidos, tuvo a la vez la virtud de haber zanjado varias diferencias que trascendieron en fuertes polémicas que se hicieron públicas entre la publicación de su comunicado resumen inicial de 10 puntos en septiembre de 2015 y la publicación posterior y completa del texto del acuerdo de 75 puntos en el siguiente mes de diciembre (pág. web altocomisionadoparalapaz.gov.co).

\section{Cuestionamientos e imprecisiones frecuentes sobre el proceso de paz}

Aún no existe un consenso nacional por la paz, si bien la mayoría de partidos políticos, organizaciones de la sociedad civil, instituciones y sectores de opinión, coincide en la necesidad de la solución política con las dos guerrillas existentes, existen también márgenes apreciables de ellos que cuestionan, discuten o rechazan las conversaciones y negociaciones de paz en curso. Se registran variaciones apreciables en las coyunturas, de forma que cuando hay avances notables en la mesa y merman las expresiones de guerra y violencia, suben las simpatías y el respaldo al proceso de paz. Por el contrario, ante crisis en las conversaciones o ruptura del cese al fuego y ataques que afectan a sectores de la población y medio ambiente, ascienden el pesimismo y la oposición al proceso de paz, a tal punto que en ocasiones ha llegado a equiparar o a superar los respaldos.

Son muchas y de diverso tono las discusiones registradas de las que no podríamos dar cuenta con facilidad y con extensión de ellas, pero podemos advertir sobre algunas de las que más han trascendido. Pero, adicionalmente, es preciso distinguir, más allá del legítimo y necesario debate en torno a los múltiples dilemas y matices que surgen, dos situaciones a la vez diferenciadas: quienes se oponen de manera vertical y sectaria al proceso de paz y quienes llegan al sabotaje o ataque contra el proceso de paz y sus participantes. Estos tres asuntos han tenido presencia, aunque encuentren puntos de relación o mutación entre ellos.

Muchos de quienes apoyan el proceso de paz tienen opiniones críticas frente a él, caso del partido PDA (Polo Democrático Alternativo) y de numerosas organizaciones sociales del ámbito popular, que especialmente debaten en torno a las premisas insuficientes y en políticas oficiales incoherentes con el anhelo de una paz sostenible. Pocos sectores se oponen de manera cerrada al proceso, casos del partido CD (Centro Democrático) y del procurador general, que han tomado como bandera las exigencias en justicia señalando de impunidad cualquier medida de transición propia de un proceso de paz. Y se han presentado focos de sabotaje contra el proceso de paz, que tienden a disminuir su actuación ante la fuerza que cobra, algunos ligados al CD y 
varios de sus dirigentes y otros no claramente establecidos, existen sospechas sobre compromiso de sectores o personas en el seno de la fuerza pública y organismos de seguridad estatal.

Se discute si los dos mandatos consecutivos del presidente Uribe (2002-2010) crearon las condiciones favorables para el proceso de paz, una vez que el notable debilitamiento de las guerrillas les exigió pasar a las conversaciones para desistir del alzamiento, o si fue una acción de fuerza estatal no exitosa, sino altamente afectada por violaciones a los derechos humanos, en especial por ejecuciones extrajudiciales, a la vez que sus propuestas de cese unilateral, acogimiento de la reintegración e indulto o sometimiento a la justicia fracasaron con las guerrillas y tuvieron particular aplicación con los paramilitares, dado su carácter y sus nexos reconocidos con el Estado y ámbitos gubernamentales.

"Sin la mano dura de Álvaro Uribe, nunca se hubiera podido llegar al punto de inflexión que se dio...". (Revista Semana, 2015, nov., p. 23).

Sin pretender cerrar esta discusión, puede afirmarse que no hay contradicción insalvable entre ambas apreciaciones, pero sí existen discusiones importantes al respecto. Las administraciones de Uribe sí atacaron, golpearon y consiguieron replegar y mermar la actuación insurgente, aunque no aniquilaron -como se suponía- a la insurgencia. Consiguieron cambiar la relación de fuerzas, lo cual incide en la propia insurgencia para disponerse a la negociación de paz. Pero, a la vez, resulta cierto que desde antes las guerrillas tenían propuesta y niveles de disposición para la solución negociada. De hecho, el ELN lo intentó con Uribe, y de forma que las FARC no toman la decisión de negociar la paz en razón de la referida ofensiva militar, sino en atención a varios factores, siendo muy importante la valoración que hace del cambio de política en el tratamiento del conflicto al asumir el presidente Santos.

También resulta cierto que la actuación de la Fuerza Pública y los organismos de seguridad en el marco del conflicto armado y en el plano general de su actuación estuvieron en buen grado deslegitimadas por los compromisos de violación a los derechos humanos -en especial las ejecuciones extrajudiciales de la Fuerza Pública y las acciones arbitrarias de espionaje ilegal y persecución sistemática del DAS-. Más aun, en un contexto más general, puede afirmarse que el segundo mandato del presidente Uribe fue ilegítimo, a la luz de la Constitución Política y la ley, debido a los delitos a los que se recurrió desde el propio Gobierno para lograrlo, hechos ya sustentados por fallos judiciales.

Desde el inicio y permanentemente se ha discutido sobre si resultan aceptables los tiempos del proceso de paz. El Gobierno esperaba una paz inmediata, "en términos de meses", otros sectores advertían que se requerían tiempos más amplios; pero esta 
tensión no cesa, pues algunos sectores, oficiales, de prensa y opinión, mantienen permanente desacuerdo y por tanto crítica a los tiempos empleados en el logro de los acuerdos conseguidos.

"El proceso ha tomado mucho más del tiempo del esperado (...) la demora ha agotado la paciencia colectiva" (Revista Semana, 2015, sep., p. 23).

El experto Vicen Fisas, al inicio de esta discusión, publicó una tabla sobre los tiempos empleados por distintos procesos de paz en el mundo, la cual permitía concluir que en casos como el nuestro, de entre tres y cuatro años de duración, podía afirmarse que resulta ser de los procesos de negociación de paz más breves y ágiles del mundo, pues algunos incluso se aproximan y superan la década (Fisas, 2015, p. 143-144).

Sin embargo, es de advertir que al respecto no existe una fórmula rígida y que las coyunturas y factores de diverso orden hacen relativos los tiempos en cada caso. Pero sí puede afirmarse que incluso en nuestro país, aún las negociaciones de paz prontas y ágiles como las del M19, que previamente había tomado la decisión de desmovilizarse y pasar a la vida política legal, y la del EPL, que aceleró su negociación de paz, puesto que se dio en el contexto de la Asamblea Nacional Constituyente, su convocatoria y realización, ambas duraron alrededor de un año. Incluso sin considerar en ambos casos antecedentes como intermediaciones, treguas unilaterales, como gesto para demandar el inicio de las conversaciones y otros hechos que se inscribieron en el proceso de paz, lo cual al menos duplicaría tal tiempo.

Como lo evidencia la anterior síntesis sobre los acuerdos parciales conseguidos y las comisiones y subcomisiones en funcionamiento, el tiempo empleado con las FARC, de tres años en la actualidad y una proyección a un cuarto año, con la finalización definitiva del conflicto armado ya prevista, permite afirmar que es un tiempo explicable y razonable. Además, el debate sobre la impaciencia ciudadana se relaciona más con los tiempos contra los logros reales, o el escepticismo y la desconfianza, bien cuando no se evidencian resultados hacia la paz o cobran fuerza hechos de violencia o discrepancias públicas enconadas entre las partes. Por supuesto, que con ello no se desconocen también expresiones desde las guerrillas de una concepción del tiempo dilatada, que no se corresponde con tiempos y dinámicas políticas en curso necesarias de resolver. E incluso, en el caso de la otra guerrilla, a todas luces el Gobierno nacional y el ELN le deben una explicación al país y a la opinión internacional, de porqué una tan dilatada fase de exploraciones sin que se inicie la mesa de conversación y negociación pública.

Otra discusión se refleja en que las dirigencias de los partidos tradicionales, líderes gremiales y los principales medios de prensa, de forma unilateral exigen las manifestaciones de confianza y los gestos a favor de la paz y las soluciones humanitarias 
siempre con carga a las guerrillas, y por lo regular dejan de hacerlo hacia el Estado, el Gobierno y la propia sociedad. Ya lo advertía en una columna de opinión Víctor Currea de Lugo con referencia a la exploración con el ELN, cuando muchas voces sin conocimiento de lo sucedido, dado el carácter confidencial de las sesiones exploratorias, dan por hecho siempre a priori que la responsabilidad en la dilatación en el tiempo, ya por un año en esta fase sin resultado, sería solo responsabilidad de esa guerrilla. La validez de las exigencias y críticas desde la sociedad y las instituciones debe sustentarse en analizar las posiciones de las partes, las propuestas en discusión, la metodología, las condiciones y dinámicas de trabajo, las dificultades, tensiones y todo lo ocurrido en la mesa.

Sobre esta discusión Ilama la atención el que recientemente el propio presidente Santos, al conceder el indulto a un grupo de integrantes de las FARC, declaró que lo hacía como gesto de entendimiento gubernamental, en reciprocidad, dado que los reportes oficiales y de otros entes de la sociedad civil confirmaban el cumplimiento del cese al fuego unilateral por parte de las FARC. Sin embargo, algunas informaciones y opiniones de medios de prensa se apresuraron a repetir, en contra de la explicación presidencial, que tal hecho presuponía una exigencia a las FARC de producir un gesto unilateral que se entendía no realizado.

(...) si las FARC no hacen un gesto recíproco, quedarían mal paradas (...) El problema es que estas medidas no tengan respuestas recíprocas y no signifiquen, como deberían hacerlo, un salto adelante para la Mesa (...) Una opinión pública que ve el indulto cono un gesto tangible de perdón, sin una reciprocidad de las FARC. (Semana, No. 1752., 2015, página 28).

Es necesario exigir gestos y compromisos con la paz, el desescalamiento militar y la observancia perentoria del derecho humanitario a las partes del conflicto, pues hay que tener presente que tales obligaciones también le corresponde a la parte estatal y gubernamental y que no resulta constructivo para un manejo imparcial de la información y los análisis sesgar la interpretación invariablemente en contra de la insurgencia.

"El país quiere algún tipo de castigo para las FARC" (Revista Semana, 2015, nov. P. 32).

Al respecto aparece otra discusión en igual sentido, pues se repite con mucha frecuencia en distintos medios de prensa y opinión que supuestamente la exigencia ciudadana se centra en la exigencia del castigo penal contra las guerrillas, en especial contra las FARC, sin considerar tal exigencia o guardando silencio con relación a la exigencia que también se hace frente a los otros actores del conflicto. A propósito, distintas encuestas han revelado en años recientes que tales exigencias se hacen en porcentajes 
mayoritarios, de forma igual e incluso con mayor énfasis ante los responsables estatales, a la vez la demanda se hace igual para los paramilitares y los guerrilleros.

Entre otras fuentes, la encuesta realizada por el Centro Nacional de Memoria Histórica, la Universidad de los Andes y la Fundación Social, con apoyo en IPSOS Napoleón Franco, en 2012, reveló que la población encuestada en distintas regiones y niveles de municipios del país expresaba en general igual rechazo y exigencia de justicia ante las responsabilidades por violaciones del Estado, los paramilitares y las guerrillas. En particular, el 70 \% de la población consideró igual de graves las violaciones de paramilitares y guerrilleros, el $72 \%$ rechazó el que se hubiera recurrido a los paramilitares y el $72 \%$ se manifestó de acuerdo en que los miembros de la Fuerza Pública que han cometido violaciones deben ser "castigados con la mayor severidad puesto que el Estado debe ser el primero en respetar los derechos humanos en toda circunstancia" (Centro de Memoria Histórica et al., 2012, p. 23-27).

En el caso de los daños causados por la Fuerza Pública (...) la mayoría de las personas encuestadas se manifestaron a favor de que los agentes fueran castigados con la máxima severidad posible: $73 \%$ de Afectados, $66 \%$ de No Afectados, $76 \%$ de Víctimas Organizadas y $75 \%$ de Expertos prefirieron este planteamiento, que además incluye la afirmación de que el Estado debe ser el primero en respetar los derechos humanos bajo cualquier circunstancia. (Centro de Memoria Histórica et al., 2012, p. 26).

Y a veces, más allá de las discusiones, las informaciones de prensa se distancian del rigor en la interpretación de los acuerdos conseguidos, o hacen deducciones que en algunos casos pueden resultar equivocadas, lo que incide negativamente en la opinión sobre temas de alto interés relativos a la búsqueda de la paz. Entre los ejemplos posibles, hay que afirmar que los acuerdos en justicia con las FARC no tendrían validez en la negociación con el ELN, cuando al respecto nada puede afirmarse, puesto que esto solo lo definirán en su momento oportuno las delegaciones del Gobierno nacional y del ELN en la respectiva mesa de conversaciones y negociación (EI Tiempo, 2015, sep. 24, p. 2).

\section{Oposición intransigente y uso de falacias contra el proceso de paz}

Al inicio del proceso de paz, desde el expresidente Álvaro Uribe y varios de los dirigentes del Partido Centro Democrático (CD) se expresaron no solo argumentos de cuestionamiento y rechazo total al proceso de paz, sino que se utilizaron actos que pueden caracterizarse de ataque y sabotaje, los cuales han sido una constante hasta la actualidad. Más allá del necesario debate político, el uso en muchos de ellos del recurso de mentiras, tergiversaciones y falacias en el empeño de contrainformar y 
desacreditar el proceso de paz. Sobre tales actos reprobables sobresalen y están por cuenta de las investigaciones judiciales y administrativas, dado el tipo de responsables, la interceptación de información de seguridad nacional y el hacerla pública, sobre desplazamiento de voceros insurgentes hacia los eventos de diálogo, lo que generó graves riesgos de seguridad. Con desfachatez, el expresidente difundía en sus propias cuentas de redes sociales este tipo de información, para sustentar interpretaciones en el sentido anotado.

Otro caso sobresaliente fue el montaje de un sitio de espionaje y contrainformación ilegal, abiertamente contra el proceso de paz y sus delegaciones en la mesa de La Habana, incluido el propio Gobierno, hecha directamente por el candidato presidencial del CD, Óscar Iván Zuluaga, y sus inmediatos colaboradores.

El columnista Antonio Caballero recientemente se refirió a nueve de las frecuentes mentiras difundidas por el expresidente Uribe y su partido CD, en aras de desprestigiar el proceso de paz: "...la palabra dejación de armas equivale a que el terrorismo las mantenga y las use cuando quiera", "Venezuela acribilló con genocidio a centenares de familias colombianas", "las facultades ilimitadas al gobierno constituirían una nueva dictadura respaldada por los fusiles y explosivos del terrorismo" (Caballero, 2015, p. 153).

Tales expresiones desconocen el sentido real del desarme guerrillero comprometido. Hablar con despropósito y lejos de cualquier consideración con seriedad técnica y política con respecto a lo ocurrido en las recientes tensiones con Venezuela. Señalar propósitos autoritarios al presidente Santos con base en "facultades ilimitadas", cuando el proyecto de Acto Legislativo referido solo se limita a la presentación de iniciativas con base en los textos suscritos en los acuerdos de paz.

En la misma línea de oposición obcecada y de tergiversación de las posiciones, propuestas y acuerdos entre las partes en el proceso de paz, el procurador general Alejandro Ordoñez, desconociendo el alto perfil, la seriedad y la misión constitucional relacionada con los derechos humanos y la actuación de control estatal por excelencia, permanentemente opina para atizar polémicas y entrega afirmaciones con frecuencia parciales, viciadas o descalificadoras. Entre ellas, afirmar que lo convenido en un mes de La Habana en materia de justicia "es una comedia", "una alianza del presidente Santos con las FARC para encarcelar al expresidente Uribe", "un mecanismo de venganza".

Así mismo, otros voceros de la extrema derecha opuesta a las conversaciones de paz, con referencia al mismo tema recurren a lo que constituye una verdadera falacia, dada la falta de conexión con la realidad, pero afirmándolo como cierto: "...tendremos una justicia que dará beneficios a los autores de los crímenes atroces como los de 
Bojayá y EI Nogal y dejará tras las rejas a los militares que los han combatido con rectitud y valor" (Apuleyo, 2015, p. 15).

El Gobierno nacional desde 2014, en varias oportunidades intentó un entendimiento político con el expresidente Uribe y su partido CD y de nuevo lo buscó hacia septiembre de 2015, con especial colaboración de Estados Unidos, a través de su enviado especial para el proceso de paz Bernie Aronson, como de su embajador Kevin Whitaker. Se produjeron, entonces, encuentros con este líder de la oposición al proceso de paz, con asistencia del jefe de la delegación gubernamental en la mesa, Humberto de La Calle, y del ministro de Defensa, Luis Carlos Villegas, sin resultados. Uribe mantuvo una posición cerrada de descalificación a los acuerdos conseguidos, de rechazo a la fórmula en justicia, al proyecto legislativo sobre mecanismo de refrendación y agilización de las reformas por implementar y aseveró que la política de paz gubernamental Ilevaba al fortalecimiento de las FARC, la inseguridad y el incremento de los cultivos de uso ilícito.

No obstante, el ministro del Interior, Juan Fernando Cristo, en el trámite actual del proyecto de Acto Legislativo para la Paz ha declarado la búsqueda desde el gobierno de "un acercamiento constructivo con la oposición, bien del CD o del PDA".

Muchos sectores de opinión buscan un consenso nacional lo más amplio y mayoritario para hacer viable el respaldo y la legitimidad del proceso de paz. Pero, mientras persista la imposibilidad de acuerdos con el sector de oposición cerrada referido, también hay conciencia de que la paz podría lograrse con apoyo de amplias mayorías y con un margen de oposición minoritaria, aunque esto no significaría desmayar en los esfuerzos por la búsqueda de un consenso nacional y de crear condiciones para una reconciliación en condiciones de dignidad y en coherencia con los propósitos de democratización, inclusión y reforma social inherentes a una paz sostenible.

No puedo ocultar que un viraje de Uribe sería trascendental para la reconciliación del país. También un cambio de actitud del procurador Alejandro Ordoñez. Como están las cosas, ellos dos no son imprescindibles para la firma del acuerdo de paz. Pero, sin duda, son decisivos para acelerar la reconciliación del país y la normalización de la democracia. Sin ellos el posconflicto será difícil y prolongado. (León Valencia, Semana, 2015, sep., p. 51).

\section{El proceso en 2015: avances, crisis y notable recuperación}

En los tres primeros meses de 2015 se registró un avance en las conversaciones en medio de una situación positiva de desescalamiento militar soportada en la tregua unilateral de las FARC y la suspensión de bombardeos de las Fuerzas Militares. Se avanzó en el acuerdo especial humanitario hacia el desminado de territorios, con un 
proyecto piloto iniciado en Antioquia que implicó la participación de delegados de las partes, guerrilleros conocedores del terreno y estructuras militares oficiales con experticia en la materia. Se sucedieron las delegaciones de víctimas de manera que su composición, propuestas y testimonios produjeron en el país un necesario debate sobre la necesidad de su plural reconocimiento y atención.

Sin embargo, tras varios incidentes por acciones militares que los afectaban, denunciadas por las FARC, esta guerrilla realizó en el mes de abril un fuerte y cruento ataque contra el Ejército en Cauca, lo que rompió la tregua con negativos efectos. Fue amplio el rechazo de numerosos sectores políticos y medios de prensa a la actitud guerrillera, pero también al hecho de que esta guerrilla continuó con una serie de ataques contra la infraestructura pública de servicios y la red petrolera, con afectación a poblaciones y al medio ambiente. En el curso de los dos meses siguientes, Ios operativos militares oficiales produjeron decenas de bajas en las FARC, a partir de la reanudación de los bombardeos aéreos contra sus campamentos. Estas situaciones de guerra y violencia debilitaron pronto el respaldo al proceso de paz, a tal punto que desde partidos políticos y otras voces críticas y opositoras se llegó a reclamar suspender las negociaciones, acabar con el proceso de paz o imponerle un plazo perentorio para culminarlo o acabarlo.

A tono con esta situación, se invirtió la opinión favorable mayoritaria por la desfavorable y cobraron aliento las voces que reclamaban el retorno al tratamiento militar para de nuevo intentar aniquilar las guerrillas. Según una encuesta de Gallup Pollo en junio de 2015, el $62 \%$ no creía en que se lograran resultados de paz en la mesa de La Habana, el $42 \%$ se manifestaba por la solución política del conflicto armado y el $45 \%$ se manifestaba partidario de la opción militar.

Entre las presiones, el expresidente Uribe, con incoherencia para el propio Gobierno, el vicepresidente Vargas Lleras y parlamentarios, incluidos sectores de la Unidad Nacional, propusieron entonces la suspensión del diálogo y la imposición unilateral por el Gobierno de una fecha de terminación de la negociación. Sin embargo, el presidente Santos replicó: "no creo en plazos fatales, pero es necesario agilizar la negociación". Entre otras opiniones progresistas y a favor del proceso de paz, en el mes de junio la periodista Cecilia Orozco replicó: "...no valoraron el cese del fuego de las FARC pero su ruptura y el tipo de ataques que hace ahora esta guerrilla hace el juego a la ultraderecha opuesta a la paz (...) al gobierno se le estrecha el margen de maniobra". En igual sentido se manifestó el reconocido académico Rodolfo Arango: "...las FARC subestiman de nuevo el poder desestabilizador de los enemigos del proceso, la amenaza guerrerista con sus extensos intereses económicos y políticos". A su vez, Francisco Leal Buitrago expresó: "La tregua de las FARC fue despreciada por la derecha recalcitrante", pero también afirmó que: "los actos demenciales de las FARC deterioraron aún más su imagen, arrastrando consigo la del proceso de paz". 
Ante las exigencias de claridad con lo sucedido en el proceso, el jefe de la comisión negociadora del Gobierno, Humberto de la Calle, concedió una entrevista que fue difundida ampliamente, en la que además del rechazo al tipo de actuaciones de las FARC, no dirigidas a enfrentamientos con la fuerza pública, sino contra bienes públicos civiles, con afectación de la población y el ecosistema, puso de presente que de no superarse la situación de violencia y el poco avance hacia nuevos acuerdos, el Gobierno podría abandonar la mesa, pero a la vez dejó abierta la puerta a la recuperación del entendimiento, al declarar que el Gobierno podría considerar un cese al fuego bilateral, a condición de ser definitivo y verificable, precisamente cuando las FARC planteaban que era necesario un cese al fuego bilateral para garantizar el ambiente de la negociación.

...lo que está ocurriendo es insoportable (...) los ataques no son contra el Ejército, ni contra la que Ilaman la oligarquía sino contra el común de la población y contra el medio ambiente (...) esta situación ha llevado al proceso de paz a su peor momento. Estamos dispuestos a un cese al fuego, aún antes de la firma del acuerdo, en la medida en que sea serio, bilateral, definitivo y verificable; siempre y cuando tengamos la garantía de que ellos asuman su responsabilidad (las FARC) y que exista verificación nacional e internacional.

La guerra estratégica ya terminó y el Estado la ganó. (...) Perdieron la guerra, pero insisten en su condición de rebeldes (...) Las FARC han sido el elemento más conservador en la vida colombiana, cincuenta años de violencia disolvieron prácticamente al movimiento sindical y estudiantil. (...) el gobierno podría levantarse de la mesa. (Gossaín, 2015, p. 4-6).

Era un momento de alta tensión entre las partes y de consideración real sobre si podría cuajar o fracasar el proceso de paz, a juicio del Gobierno. De La Calle increpó a las FARC, con razón, también en lo relativo al fracaso de su opción revolucionaria estratégica, pero dejó entrever a la vez posiciones y opiniones discutibles. El considerar el abandono de la mesa contrariaba la metodología acordada, por segunda vez desde el Gobierno, incluso variando la anterior posición de dialogar en el exterior independientemente de las condiciones de la confrontación interna. Posición entendible como presión a la contraparte, pero cuestionable por el riesgo para el curso del proceso. Y, a la vez, muy discutible atribuir a las FARC unilateralmente la prolongación de la violencia e incluso a renglón seguido asociar la "disolución del movimiento sindical y estudiantil", más que impreciso resultaba inconsecuente, si se considera la evidencia de la responsabilidad estatal directa, en la acción de extermino ejercida por entes estatales y paraestatales, en sus acciones de persecución y exterminio, por lo regular coordinadas o al menos toleradas de los primeros frente a los segundos. 
El proceso de paz Gobierno-FARC había entrado en la crisis más difícil, con retroceso en el ambiente de distensión militar anterior y con pérdida de iniciativa política y carente de resultados de mayor significación, por cuanto si bien se avanzaba en el tema de víctimas y en varios de sus tópicos, las críticas pusieron de presente que se había cumplido un año tratando en la mesa este tema sin resultado final. En tal coyuntura resultó decisiva la positiva actitud de los países garantes en la mesa, Cuba y Noruega, y acompañantes, Venezuela y Chile, de forma que jugaron una iniciativa con matiz de rol mediador, justo en busca de recuperar la dinámica positiva del proceso. Entregaron entonces una propuesta a las partes con cuatro consideraciones: mantener la mesa de negociación, avanzar hacia el pronto logro de un cese al fuego bilateral, que implicara retomar la dinámica de desescalamiento militar, acordar una nueva dinámica de agilización de las conversaciones para conseguir pronto entregar nuevos acuerdos parciales de la agenda y recuperar la confianza.

En efecto, durante el ciclo 38 de las conversaciones, el 7 de julio de 2015, los países garantes y facilitadores en comunicación escrita entregaron tales solicitudes al Gobierno y a las FARC. El presidente Santos declaró acuerdo, pero advirtió que un cese bilateral y definitivo exigía que fuera "serio, verificable y con avance suficiente en todos Ios temas" de la agenda de conversaciones. De La Calle precisó que el Gobierno variaba la posición de conseguir el cese al fuego bilateral al final de los acuerdos, con disposición a que fuera antes, "siempre y cuando tengamos garantía de que ellos asuman responsabilidad en materia judicial y la verificación". Las FARC reiteraron su disposición a conseguir un acuerdo definitivo de paz con el presidente Santos.

En esta nueva tónica, el 9 de julio las FARC anunciaron que el siguiente 20 de julio declararían un nuevo cese al fuego por un mes "a condición de no ser atacadas" y solicitó veeduría del Frente Amplio por la Paz (FAP), de la Iglesia católica y del movimiento constituyente por la paz. El presidente Santos, el 13 de julio siguiente, condicionó unilateralmente la continuidad del proceso de paz, a cuatro meses, momento en el cual advirtió que se revisaría "si las FARC cumplen", para tomar la decisión de continuar o no. Luego se produjo un acuerdo entre las partes, el 12 de julio, sobre desescalamiento, verificación internacional con invitación inmediata a la ONU y a UNASUR a participar en la Subcomisión Técnica Fin del Conflicto para avanzar en sus preparativos, de manera que se avanzara hacia "acordar sin demoras los términos del cese al fuego y las hostilidades bilateral y definitivo, y la dejación de las armas, incluyendo el sistema de monitoreo y verificación".

Se agotó entonces el esquema del Gobierno de negociar en medio de la ofensiva militar oficial con prioridad de causar bajas selectivas en los mandos de las FARC. EI presidente Santos, en alocución al país el 12 de julio, precisó: "Los colombianos cada vez entienden menos que en La Habana se hable de paz mientras en Colombia continúan los ataques y los muertos". "Si la guerrilla suspende su ofensiva terrorista, 
el gobierno procederá a des-escalar las acciones militares". Al hacerse efectivo el nuevo cese al fuego de las FARC, el25 de julio siguiente el Gobierno suspendió los bombardeos, y el ministro de Defensa, Luis Carlos Villegas, declaró que se mantenía tal actitud "sólo si los campamentos están alejados de los cascos urbanos y no amenazan a la población civil".

Así mismo, se varió la metodología de construcción de acuerdos sobre los temas restantes de la agenda, con el nuevo elemento no solo de simultaneidad para avanzar en los temas, sino de conseguir acuerdos puntuales y efectos de aplicación inmediata. Además, resultó una medida de gran calado el ampliar el acompañamiento internacional directo en las comisiones de conversaciones y búsqueda de acuerdos, con la importante inclusión en las comisiones temáticas a la ONU y UNASUR; a lo que se agregaba el desarrollo del plan piloto de desminado con acompañamiento de una entidad de Noruega y el anuncio de la preparación de un plan piloto de sustitución de cultivos de uso ilícito. En este punto se zanjó la crisis. De nuevo se oyeron voces optimistas. Iván Márquez, jefe de delegación de las FARC, declaró que se trataba de un "relanzamiento vigoroso, prometedor y esperanzador"2.

Se hizo notorio un mayor ritmo de la negociación. Con apoyo internacional, la Subcomisión Fin del Conflicto se empañaba con énfasis en la búsqueda de consensos sobre el cese bilateral definitivo y las formas de verificación y monitoreo. La Subcomisión de Género, liderada por María Paulina Riveros del Gobierno y Victoria Sandino de las FARC, avanzaba en consultas y tratamiento de propuestas, con una experiencia pionera en negociaciones de paz. Se integró una comisión de asesores de las partes en el tema de justicia, con evidente ritmo de agilización de la búsqueda de consensos. El respaldo de la comunidad internacional se reforzó con declaraciones del papa Francisco a favor del proceso de paz en Colombia, con alta repercusión en su viaje a Cuba.

Por su parte, la ONU, a través de su delegado Fabrizio Hochschild, en lo referente al alivio humanitario que en perspectiva temporal se conseguía con el proceso de paz, informó que entre noviembre de 2012 y junio de 2015, se verificaba la disminución en las formas de victimización de población civil y el impacto humanitario del conflicto armado $^{3}$. Más aun, a partir de su labor de monitoreo al cese al fuego y al conflicto armado, el Centro de Estudios CERAC aseveró que según los reportes históricos en

2 Esto, a pesar de que las FARC denuncian que continúan operativos en su contra en varias regiones y, según su versión, bombardeos en Putumayo; hecho que, señalaron, ponía en riesgo la tregua unilateral retomada. El ministro de Defensa replicó afirmando que la suspensión de bombardeos no implicaba el cese de otro tipo de acciones militares y negó que existieran bombardeos contra las FARC.

3 La ONU precisó que había decrecimiento del $27 \%$ del desplazamiento forzado, del $48 \%$ de minas antipersonal, aunque se registran 37 homicidios contra personas defensoras de derechos humanos. 
2015 se registró el menor número de víctimas civiles ocasionadas en el contexto del conflicto armado, en comparación con los volúmenes de violaciones sucedidas desde 1974.

Se produjo, entonces, el importante acuerdo sobre víctimas relativo al Sistema de Verdad, Justicia y Reparación, que incluyó la conformación de una Jurisdicción Especial de Paz, estableciendo una fórmula de penas alternativas y compromisos con revelaciones de verdad y reparación de las víctimas, para un tratamiento "equitativo y equilibrado" hacia todos los responsables, combatientes y no combatientes, implicados en graves violaciones, a la vez que se incluyó una amnistía general para las FARC, excepto para quienes tuvieran responsabilidad directa en graves violaciones. Dada la relevancia de este hecho, el presidente Santos asistió directamente a Cuba al acto de protocolización de este acuerdo, que acompañó directamente el presidente Raúl Castro, y sostuvo una reunión directa con el comandante en jefe de las FARC, "Timochenko", en la cual acordaron la fecha del 23 de marzo de 2016 para la firma del acuerdo general final y en los 60 días siguientes, la dejación de armas de esta guerrilla.

Con tan importantes decisiones que tuvieron alto impacto internacional, el presidente Santos asistió de inmediato a la 70 Asamblea General de la ONU, que contó con la participación de 193 jefes de Estado, ante los cuales informó sobre el avance de los acuerdos de paz y prometió que en la Asamblea del año siguiente en Colombia se habrá firmado la paz de manera definitiva. Destacó así mismo, que el acuerdo logrado en justicia transicional asumía con claridad el compromiso con los derechos de las víctimas, la no impunidad y que un acuerdo anterior había convertido a la guerrilla en aliada para superar la economía de drogas ilegales.

En consecuencia, a inicio de octubre de 2015 una nueva encuesta de Ipsos-Napoleón Franco estableció que existía un creciente optimismo en que habría resultado final en los diálogos, con notable ascenso: para julio era $29 \%$, para octubre $46 \%$; a la vez, el $55 \%$ consideró positivo el encuentro Santos-Rodrigo Londoño ("Timochenko") y el $67 \%$ estuvo de acuerdo en la continuación de los diálogos, frente a un $33 \%$ que estimaba que debía combatirse a la guerrilla. Ese mismo mes, otra encuestadora, el Centro Nacional de Consultoría, estableció un apoyo a los diálogos de paz del 73 \%.

\section{Acuerdo en justicia: debate necesario e inoportuno litigio entre las partes}

El acuerdo sobre el marco jurídico se enfocó en la justicia restaurativa, sin desconocer implicaciones en justicia retributiva y penal. No se adoptó la selección ni la priorización de casos, pero sí el tratamiento diferenciado, de manera que estableció un marco jurídico con beneficios alternativos definido frente a graves delitos, para aplicar a los actores armados y civiles comprometidos en el contexto del conflicto armado. Como 
era de esperarse y lo advirtió el presidente Santos, el acuerdo sobre justicia produciría un intenso debate interno con repercusiones internacionales, lo cual podría haberlo fortalecido al momento.

Sin embargo, más allá de la necesaria controversia con las interpretaciones y las diversas posturas ante el tema y el propio proceso de paz, el que el Gobierno y las FARC entraran de inmediato a discrepar públicamente y con pugnacidad sobre elementos muy sensibles del acuerdo, creó desconcierto y debilitó de forma pronta, lamentablemente, los positivos efectos logrados en el ambiente nacional ahora favorable al proceso de paz. El mecanismo normal de haber dado a conocer el acuerdo inicialmente en un texto resumen de diez puntos, dio lugar luego a debates no zanjados sobre el texto general del tema, de 75, lo cual evidenció las discrepancias y convirtió en hecho público desgastante el que Gobierno y FARC tuvieran que concertar de nuevo la retoma del apoyo en la Comisión Jurídica de expertos de las partes ${ }^{4}$, para solucionar las diferencias y entregar el texto general consolidado y consensuado.

Inicialmente, los pronunciamientos internacionales de apoyo al acuerdo sobre justicia fueron dicientes, entre ellos el del secretario general de la ONU Ban Ki-noom. El relator de este organismo para los derechos de las víctimas, el colombiano Pablo de Greiff, advirtió que la justicia de transición era por su naturaleza imperfecta, propia de "tiempos radicalmente imperfectos" y de forma que "no puede evaluarse con los estándares de la justicia ordinaria en tiempos de paz". La fiscal general de la CPI, Fatou Besouda, declaró: "Noto con optimismo que el acuerdo excluye la concesión de amnistías por crímenes de guerra y crímenes de lesa humanidad y que está diseñado, entre otras cosas, parta poner fin a la inmunidad por los crímenes más graves". (Revista Semana, 2015, sep., Declaraciones de Fatou Besouda, p. 32). Y anunció que revisaría en detalle la Jurisdicción Especial de Paz, con consideración al examen preliminar por la situación de los derechos humanos en que se encuentra Colombia ante ese organismo. (EI Tiempo, 2015, 24 de sep., p. 2).

Vicent Fisas, experto en el seguimiento mundial a los procesos de paz, estimó que era el primer acuerdo de paz en el mundo que incluía medidas de justicia restaurativa. No obstante, desde las organizaciones de derechos humanos con reconocimiento internacional, el director ejecutivo para las Américas de Human Rights Watch, José Miguel Vivanco, expresó discrepancia con la forma de restricción de la libertad que para graves delitos tenía la opción de no pago de pena en centros carcelarios: "...sin perjuicio de que el acuerdo contempla esfuerzos para promover la rendición de cuentas por violaciones de derechos humanos, lo cierto es que este permitirá que los máximos

4 Juan Carlos Henao, Manuel José Cepeda y Douglas Cassel por el Gobierno nacional y Álvaro Leyva, Darío Martínez y Enrique Santiago por las FARC-EP. 
responsables de los peores abusos puedan eximirse de pasar siquiera solo un día en prisión. Es difícil imaginar que esta forma de justicia transicional supere un escrutinio de la Corte Constitucional o en última instancia de la Corte Penal Internacional". (EI Tiempo, 2015, 24 de sep., p. 8).

Por su parte, el directivo internacional de ICTJ, Eduardo González, argumentó que "...si es que existe un proceso genuino, pueden justificar que se suspenda la relación de proporcionalidad entre la gravedad de un delito y la pena". Señaló que la Jurisdicción Especial de Paz tendrá función de investigación como la Fiscalía y de adjudicación como un tribunal, capaz de imponer penas de manera diferenciada. $Y$ destacó que definir un tribunal internacionalizado ofrecía confianza y legitimidad, con mensaje a sectores nacionales y de la comunidad internacional. (El Espectador, 2015, 5 de oct., p. 10).

Internamente, reconocidos juristas con opinión calificada en el tema terciaron también a favor del acuerdo logrado, insistiendo en la fórmula compleja por lograr, que si bien modulaba las opciones de sanción penal, ofrecía respuestas asociadas al cumplimiento de la pena, relativas a la verdad y la reparación de las víctimas, e implicaba entender también que sin desconocer compromisos del derecho internacional, garantizaran la viabilidad del proceso de paz.

"Los estudios comparados más juiciosos, como los de Sikkink y Payne, que muestran que no es la cárcel, sino las sanciones penales de diverso tipo combinadas con otras medidas como amnistías y comisiones de la verdad, las que arrojan mejores resultados para los derechos humanos en el posconflicto". (Rodríguez, 2015, p. 23).

En igual sentido, Rodrigo Uprimny argumentó que el marco jurídico de una transición respondía a la justicia pero en consonancia con el logro de la paz:

"La justicia transicional (...) no puede ser valorada con los estándares que gobiernan a la justicia en tiempos ordinarios. Debe ser evaluada conforme a los estándares, aún en construcción, que son apropiados para estas circunstancias extraordinarias y muy difíciles, y que pueden resumirse en lo siguiente: que las víctimas sean reconocidas y reparadas hasta donde sea posible, que la verdad sea esclarecida, que haya garantías de no repetición, y que los responsables de las atrocidades rindan cuentas de sus actos y reciban sanciones apropiadas". (El Espectador, 2015, 27 de sep., p. 87).

Desde la cerrada oposición referida, el expresidente Álvaro Uribe expresó repetidamente por las redes sociales y medios de prensa desacuerdo con la opción de pena restrictiva de la libertad, pero no en cárcel ordinaria: "el gobierno ha aceptado que delincuentes responsables de atrocidades no vayan a la cárcel a condición de confesar sus crímenes". Y el procurador general, Alejando Ordóñez, exigió con 
profusas declaraciones ante distintos medios de prensa, que para todos los casos existiera privación efectiva de la libertad, bajo la consideración lineal de que se había pactado "un acuerdo de impunidad" para los delitos de lesa humanidad.

Paralelamente, fue intensa la discusión sobre el mismo acuerdo que habían conseguido entre el Gobierno y las FARC. Las FARC afirmaron que el acuerdo de 75 puntos estaba "cerrado" y que el Gobierno debía "honrar la palabra". La comisión gubernamental alegó que se había convenido el texto con algunos elementos en desarrollo, lo que "exigía terminarlo y precisarlo". Además, discutieron públicamente interpretaciones sobre la naturaleza y alcance de las restricciones de la libertad como pena alternativa, sobre los delitos conexos al delito político, las calificaciones e implicaciones de las tomas de rehenes y los secuestros y la garantía de no extradición para los guerrilleros.

El Gobierno declaraba: "No creemos que haya formas de secuestro que puedan ser objeto de amnistía" (EI Espectador, 9 de octubre, 2015, p. 4). Entre tanto, las FARC, con respecto a la no extradición, exigían garantías efectivas, para no dejar la decisión a la facultad discrecional del presidente de la República ${ }^{5}$. Sobre la restricción de la libertad, la guerrilla la explicaba como una zona y el Gobierno como un lugar específico. A la vez, sobre la elección de los magistrados del tribunal previsto, algunos sectores interpretaban críticamente que no podrían ser elegidos por el Gobierno y las FARC.

EI jefe de la comisión gubernamental en La Habana, Humberto de La Calle, declaró:

"No creemos que haya formas de secuestro que puedan ser objeto de amnistía. EI alcance y las condiciones de las garantías frente a la extradición deben ser precisados. Insistimos en que hay interpretaciones del abogado de las FARC sobre las características de la restricción de la libertad que son inaceptables y que están por debajo de los mínimos que exige la comunidad nacional e internacional". (EI Espectador, 2015, 9 de oct., p. 4).

En conclusión, este inoportuno debate afectó el alto ciudadano antes evidenciado, de forma que ratificó la particular sensibilidad y fragilidad de la opinión, influenciable en cada momento por los avance del proceso o por los momentos de retrocesos, crisis o mensajes confusos como este desde las partes en la mesa. Así, a comienzos de diciembre de 2015, otra encuesta de IPSOS-Napoleón Franco estableció que el

5 En actitud positiva, el enviado especial para el proceso de paz de E.U. Bernie Aranson, expresó entonces que su país respetará lo que decida Colombia sobre extradición de guerrilleros, posición con la cual ha sorteado discusiones ante el Congreso y sectores de opinión de ese país. 
optimismo sobre los acuerdos descendió al $38 \%$ y el pesimismo se incrementó al 60 $\%$. Solo el $35 \%$ respaldó el indulto a guerrilleros de las FARC y el 65 \% lo rechazó, el $25 \%$ afirmó que se cumplirá el plazo convenido para el acuerdo final y el $75 \%$ manifestó que no se cumpliría.

\section{EI tema que resta: fin del conflicto}

Resulta diciente que el tema faltante de acuerdo de la agenda convenida es el denominado Fin del Conflicto, lo que de por sí significa que una vez consensuado se habrán conseguido acuerdos en todos los temas, de manera que el proceso de paz concluirá con base en los acuerdos adicionales también necesarios de lograr en lo referido a la forma de refrendación ciudadana que se adopte y a los mecanismos de seguimiento, verificación y monitoreo de la aplicación de los acuerdos que se asuman.

El tema Fin del Conflicto lleva un adelanto por parte de la subcomisión técnica encargada de avanzar en el tratamiento, el cual incluye siete subtemas: 1. Cese al fuego bilateral y definitivo. 2. Dejación de las armas y reintegración a la vida civil por las FARC. 3. Intensificación por el Gobierno del combate contra las organizaciones criminales y sus redes de apoyo. Medidas contra la impunidad y la corrupción. Protección a opositores políticos, movimientos sociales de protesta y defensores de derechos humanos. 4. Promoción por el Gobierno de reformas y ajustes institucionales exigidos por la construcción de la paz. 5. Implementación de una estrategia de difusión eficaz. 6. Garantías de seguridad. 7. Con relación a las víctimas esclarecer el fenómeno paramilitar. Garantizar el paso de los integrantes de las FARC a la vida legal sin los riesgos que señalan desde el paramilitarismo; viabilizar una comisión accidental para este tema ${ }^{6}$ (pág. web avancesacuerdos.gov.co)

El tema de víctimas y justicia fue evacuado en año y medio, los demás temas de la agenda se resolvieron en promedio en seis meses, de manera que a pesar de avances existentes, el reto de la mesa, de acuerdo con lo convenido sobre fecha de finalización de los acuerdos, es evacuarlo en tres meses, asunto muy difícil, por no calificarlo prácticamente de inviable. Es de notar que los subtemas tienen implicaciones que demandan nuevos acuerdos particulares de diverso orden en cada uno. Las FARC han demandado el cese bilateral y el Gobierno llegó a considerar la posibilidad de conseguirlo para fin del 2015, a condición de que sea definitivo, pero condicionado a que cuente con veeduría internacional y concentración de las estructuras guerrilleras.

Sobre el desarme, si bien se habla de avances, es un tema simbólico y práctico muy complejo y delicado de resolver. $\mathrm{Y}$ con consideraciones en varios tópicos, el temas

6 Comisión creada en septiembre de 2015, encabezada desde el Gobierno por el exgeneral de la Policía Óscar Naranjo, y desde las FARC, por el integrante del Secretariado Pablo Catatumbo. 
de garantías para el paso de la insurgencia a la actividad legal resulta ser un asunto difícil, con el peso de anteriores experiencias negativas al respecto, alto nivel de desconfianza y asunto que cuestiona la existencia de poderes regionales, alianzas y dinámicas armadas persistentes del fenómeno paramilitar, aún no cabalmente superado.

Obra a favor del avance en el tema, el que las FARC hayan prolongado el cese al fuego unilateral y que el Gobierno haya detenido los ataques aéreos y, de hecho, las campañas ofensivas, no obstante algunas denuncias de las FARC sobre ciertas incursiones en donde se ubican sus estructuras. Las vocerías guerrilleras insisten en el desmonte integral del paramilitarismo como garantía para dejar las armas y transformarse en partido político legal. Pero en todo caso ya se expresan posiciones expresas sobre el paso pronto al fin de las hostilidades, como lo ha hecho Iván Márquez ante los medios de prensa.

Se siguen construyendo consensos sobre cese al fuego y de hostilidades, bilateral y definitivo, y se avanza en el análisis del aspecto relativo a la dejación de las armas. Y sobre la reincorporación de las FARC a la vida civil, estamos listos para abordar y discutir los procedimientos para el tránsito de organización alzada en armas a movimiento político abierto. (Noticiero RCN, 2015, septiembre 17).

Aunque el Gobierno ha insistido en que el tema del futuro de la Fuerza Pública y eventuales reformas y cambios que sobre ella se adopten es asunto no tratable en la mesa de La Habana, en el marco general del avance del proceso de paz, de forma inevitable y positiva se han hecho alusiones al respecto. Así, también en septiembre de 2015 el comandante del Ejército, general José Mejía, dio a conocer públicamente que se tiene prevista una "revisión formal y total de la doctrina militar", en preparación del posconflicto. Precisó que se conformará un comando para dicha revisión. (EI Tiempo, 2015, septiembre 26, p. 2).

Adicionalmente, en lo relativo a la instalación de formas de seguimiento, veeduría y monitoreo, el Gobierno avanzó al buscar el aval de las potencias que tienen asiento permanente en el Consejo de Seguridad de la ONU (E.U., Reino Unido, Francia, China y Rusia), para lograr una resolución que defina un mandato sobre una misión de la ONU en Colombia para tales efectos. Por supuesto, de definirse esta opción, tendrá que ser consensuada entre las partes, gobierno-guerrilla, siendo ideal que este importante apoyo internacional cobijara los acuerdos previsibles también con el ELN.

Con ingenuidad, algunos medios de prensa y sectores de opinión esperaban que las FARC aceptaran concentrarse de inmediato en determinadas zonas.

"Su escenario inmediato (de las FARC) sería (...) decidirse a concentrar sus cuadrillas antes del acuerdo final de paz, para que sea verificable (el cese al fuego)... (...)...el 
punto de partida es que las FARC flexibilicen su postura (...) que las FARC se concentren antes de fin de año". (EI Tiempo, 2015, noviembre 1, p. 4).

Sin embargo, era previsible que discutieran propuestas en la mesa, desde su concepto de bilateralidad en el desescalamiento militar y garantías efectivas, por lo cual incluirían exigencias de desmilitarización con respecto a la Fuerza Pública y resistencias a la concentración, con propuestas alternas o de progresividad condicionada. Precisamente, el comandante "Timochenko" replicó en twitter ante la exigencia gubernamental de concentración, que: "las condiciones para el cese bilateral del fuego se deciden con la anuencia de las partes". Y luego anunció: "Estamos elaborando una figura de territorios de paz y reconciliación". Así, a principios de diciembre de 2015 apareció la propuesta de las FARC de "territorios de paz", que pide al Gobierno desmilitarizar zonas de presencia de sus 63 frentes, para proceder a los preparativos de la dejación de armas y a implementar medidas de seguridad, con presencia de formas de veeduría internacional y nacional, esta última con énfasis en expresiones de la sociedad civil y comunitarias.

\section{El debate sobre el mecanismo de refrendación ciudadana}

Con relación al mecanismo de refrendación ciudadana considerado en los acuerdos, la situación ha evolucionado. El Gobierno varió su propuesta inicial de un referendo, tras caer en el vacío la iniciativa legislativa al respecto, una vez que calculó de manera apresurada los tiempos y que la iniciativa no tenía consenso en la mesa. Las FARC, aunque siguen proponiendo una Asamblea Nacional Constituyente, en varios pronunciamientos han flexibilizado su posición al respecto e incluso resultó significativo que la incluyeran en su programa político, para impulsar su nuevo movimiento político en la legalidad, lo que implica que sería un propósito mediato. Desde hace tres años se discute que ni conviene el referendo porque desvertebraría los acuerdos con la posibilidad de aprobar o no cada uno de sus componentes, ni conviene la Constituyente, que significaría admitir una renegociación total de los acuerdos con un ente de composición política incierta y no necesariamente favorable a lo pactado con tanta dificultad.

Ahora, desde el Congreso, se retoma la idea expuesta con anterioridad en el debate sobre la posibilidad de recurrir a un plebiscito o a una forma de consulta popular, bien dentro de los mecanismos ordinarios, o de una forma original, o incluso como ejercicio político, pero de manera que se someta a las urnas el dilema entre aprobar (SI) o no aprobar (NO), el conjunto de los procesos de paz. Desde esta postura, además, se ha advertido que lo deseable sería que esta forma de refrendación ciudadana incluyera los pactos finales conseguidos tanto con las FARC como con el ELN, posibilidad que se aleja seriamente, ante el desfase existente entre la cercanía de la 
finalización de las negociaciones con la primera guerrilla y la dilación por más de un año del inicio de las negociaciones con la segunda.

Siempre ha sido claro que no es una obligación legal, sino una iniciativa política convenida entre las partes, el someter los acuerdos de paz al voto ciudadano. Este recurso los dota de legitimidad, movilización y participación ciudadana a su favor. Sostenibilidad, por cuanto compromete los órganos del poder público con esta forma de mandato ciudadano y además, si tiene forma legal definida, conllevaría consecuencias de carácter vinculante ante el propio Gobierno y la agenda legislativa. En determinado momento, a propósito de la iniciativa de Comisión Legislativa del Gobierno, inicialmente sin alusión a este ejercicio de refrendación, se cuestionó si se mantenía desde el ejecutivo este compromiso.

El Gobierno respondió que sí se refrendarían los acuerdos: "Nunca en los tres años que llevamos he dicho que me voy a bajar de esa promesa. Lo vuelvo a ratificar: va a haber un proceso de refrendación". (EI Espectador, 2015, 11 de sep., p. 5). Por su parte, el presidente Juan Manuel Santos declaró que la forma de ese mecanismo era lo que estaba en discusión: "Podemos utilizar algunos de los mecanismos vigentes, mecanismos nuevos, ser creativos en esta materia. Pero la promesa presidencial es intangible". (El Espectador, Declaración del presidente Juan Manuel Santos, 2015, septiembre 11, p. 5).

De manera explicable, el Gobierno, los partidos políticos partidarios del proceso de paz y otros sectores, temen a la refrendación, dado el riesgo de no alcanzar el umbral en las actuales condiciones políticas del país y ante las inadecuadas exigencias legales establecidas. Además, aunque la paz implica el más amplio consenso a su favor que debería incluir a todas las vertientes de la oposición, por las razones referidas esta situación tampoco parece realista de alcanzar. De allí que en los últimos meses de 2015 se abrió un debate en el Congreso sobre la propuesta de contar con una iniciativa que pueda dar respuesta con legitimidad y transparencia en las reglas de juego, pero también con realismo al respecto.

En tal sentido, el jurista y defensor de derechos humanos, Rodrigo Uprimny, propuso no adoptar como criterio el umbral de participación (UP) que, dadas las condiciones, centra el interés en el casi inviable logro actual de cumplirlo, debido al alto nivel de abstención predominante, de forma que podría injustamente fracasar un plebiscito por el bajo grado de participación electoral tradicionalmente existente y a pesar de tenerse notoria mayoría a favor. Por tanto, propone centrarse en el umbral de aprobación (UA), de forma que se otorguen iguales garantías y condiciones para los partidarios del SI y del NO, lo que habilitaría a recurrir legítimamente en un umbral de aprobación acorde con un volumen de participación realista, incluso como estrategia 
de enfrentar la debilidad existente en la participación ciudadana ante los asuntos de interés público.

(...) los UP paradójicamente estimulan la abstención pues los opositores de un referendo pueden preferir no votar en contra, con la esperanza de que no se alcance el umbral. Eso no es bueno para la democracia y por ello son preferibles los UA, que no tienen un sesgo pues sólo se cuentan los votos favorables para el umbral (...) (El Espectador, Rodrigo Uprimny, 2015, diciembre 6, p. 61).

\section{La iniciativa gubernamental de Comisión Especial Legislativa}

En perspectiva del desarrollo legal de los acuerdos de La Habana, el Gobierno promovió un proyecto de Acto Legislativo para facultar al presidente de la República a presentar las reformas constitucionales y legales correspondientes y así abreviar procedimientos y tiempos de aprobación en el Congreso. Se crearía una Comisión Especial Legislativa conformada por los integrantes de las comisiones primeras de Senado y Cámara y se discutió si habría otros participantes no congresistas, incluidos delegados de esta guerrilla, una vez hubiera firmado la paz y procedido al desarme.

El acto legislativo creará una comisión especial de paz y le bridará facultades al presidente de la Republica. Estamos evaluando el contenido detallado del proyecto, pero se tratará de facultades para el desarrollo agropecuario, la eliminación del narcotráfico, la participación en política y todo lo que se haya acordado en La Habana y, por supuesto, estará la comisión legislativa especial para viabilizar la implementación de Ios acuerdos (El Espectador, Declaraciones del ministro del Interior, 2015, septiembre 9, p. 2).

Se presentaron discusiones sobre si se justificaban tales medidas excepcionales y si la iniciativa tenía consenso en la mesa con las FARC, puesto que esta guerrilla declaró no conocer el proyecto y lo señaló de unilateral e inconveniente. En efecto, Iván Márquez declaró a finales de agosto que el Gobierno y varios partidos políticos desconocían los acuerdos y de manera unilateral trataban la legislación para aplicarlos, sin discutirlo en la mesa. El jefe de la delegación gubernamental en los diálogos, Humberto de La Calle, replicó por varios medios de prensa que era potestad del Gobierno asegurar los mecanismos jurídicos que permitieran materializar los acuerdos.

El Gobierno y las bancadas de su coalición o aliadas justificaron el proyecto por ser un mecanismo expedito que ahorraría tiempo y trámite en la expedición de iniciativas legales que no podrían tener modificación en su contenido básico, en virtud del respeto a los acuerdos pactados, de forma que tampoco tendría el presidente discreción para incluir otro tipo de iniciativas. Sin embargo, varios sectores advirtieron sobre el cuidado que se debía tener con la propuesta para evitar abuso frente a las facultades 
del legislativo o mecanismos que llegaran a ser inconstitucionales. Además, se ponía de presente que automáticamente obraría la revisión automática de la Corte Constitucional, en los 60 días posteriores a su aprobación.

"Esta situación excepcional requiere creatividad, claro, pero ésta debe ser cautelosa y lo más apegada posible a las salvaguardas de poderes que estableció nuestra constitución". (El Espectador, editorial, 2015, septiembre 16, p. 30).

En octubre avanzó el debate en el Congreso sobre este proyecto de Acto Legislativo. EI PDA lo objetó por considerar que no obedecía al consenso conseguido en la mesa de La Habana sobre los mecanismos de aplicación de los acuerdos y el CD se retiró del debate calificando el proyecto de "golpe de Estado" y de "justificador de partidos en armas". En la exaltación de la discusión, Roy Barreras, vocero del partido de la U, Ilegó a calificar a la bancada uribista como "nuevos terroristas". Posteriormente, una delegación parlamentaria con voceros de distintos partidos, con aval gubernamental visitó a la delegación de las FARC en La Habana, donde intercambiaron ideas sobre esta iniciativa legal.

\section{La demorada fase de exploración con el ELN}

Hemos visto que en el modelo colombiano cada una de las guerrillas desarrolló de forma independiente su propio proceso de paz, no hubo un pacto de paz simultáneo, coordinado o global. Pero, con la importancia que reviste la paz con las FARC por ser la insurgencia más histórica y de mayor capacidad bélica y de actuación en los territorios, sin que se produzca a la vez el pacto de paz con el ELN, no se podrá cerrar el ciclo de la guerra civil de las últimas décadas, correría riesgos la fase posacuerdo con las mismas FARC y se prolongaría la coyuntura histórica de simultaneidad y ambivalencias entre los proyectos de la paz y de la guerra. Por supuesto que el Estado no garantizaría, por razones evidentes, el paso de la disposición y los planes de guerra a la política y las reformas del sector de seguridad y de la fuerza pública posbélicas.

La fase exploratoria Gobierno-ELN se inició en enero de 2014 y a diciembre de 2015 cumplió dos años sin concluir el acuerdo esperado sobre agenda, reglas de juego, mesas de negociación, acompañamiento de la comunidad internacional y formas de contribución y participación de la sociedad. Es, sin duda, una prolongación excesiva y que debilita con el paso del tiempo la confluencia y complementariedad entre los dos procesos de paz que declararon las partes involucradas.

En agosto de 2015, el comandante general del ELN, Nicolás Gabino, declaró que el $90 \%$ de la agenda estaba pactada, la exploración se desarrollaba desde el año anterior mediante ciclos que rotaban entre Ecuador, Brasil y Venezuela. Incluso un mes 
después lo dejó entrever de forma más inmediata una nueva declaración del comandante "Gabino": "...nos falta el 3 \% para instalar la mesa formal de negociación (...) muy pronto tendremos buenas noticias". (Canal Capital, noticiero, entrevista con Nicolás Rodríguez, 2015, sep. 11). Según versiones que trascendieron los temas de la agenda serían: 1. Participación de la sociedad. 2. Democracia para la paz. 3. Transformaciones para la paz. 4. Víctimas. 5. Fin del conflicto armado. 6. Implementación. (EI Espectador, entrevista con Antonio García, 2015, noviembre 29, p. 16).

Han existido rumores sobre la inmediata instalación de la mesa Gobierno-ELN, el último de que sería en Caracas, pero, al parecer, por el cierre de la frontera por parte de Venezuela y la tensión tras la deportación arbitraria de familias colombianas, señaladas indiscriminadamente de tener nexos con paramilitares, habría frustrado esta posibilidad, incluso cuando se reconocía al presidente Nicolás Maduro como facilitador con esta guerrilla. UNASUR, Ecuador y Uruguay tuvieron que mediar para que retornaran los embajadores y se restableciera el entendimiento entre Colombia y Venezuela. Pero esta situación habría obligado a cambiar la sede definida. Además, los opositores al proceso de paz ante esta situación exigieron al Gobierno rechazar el rol facilitador de la República Bolivariana de Venezuela y a UNASUR como participante en las conversaciones en perspectiva de las acciones de veeduría de los acuerdos.

EI Gobierno no puede equivocarse pensando que el proceso de paz con el ELN es una repetición en menor escala del desarrollado con las FARC. Debe entender que son organizaciones insurgentes distintas, que su agenda aporta y complementa la transición a la paz y que su sensibilidad por la participación de la sociedad es positiva en una coyuntura que necesita la movilización ciudadana en respaldo a ambos pactos de paz. Así lo advierte con razón el columnista Currea de Lugo: "No van a negociar de la misma manera que las FARC". (EI Espectador, 2015, julio 15, p. 8). Y el ELN no puede equivocarse al desestimar la coyuntura histórica extraordinaria que vive el país, favorable para conseguir la solución política definitiva ante las insurgencias y al no entender que estas no viven una fase acumulativa, sino de resistencia y desgaste y que la necesidad de integrar los resultados de los proceso de paz en curso se debilitan, de manera que también afectan las propias posibilidades de su proceso de paz.

\section{Conclusión}

Colombia vive una coyuntura histórica, una estructura de oportunidad, puesto que el conflicto bélico que afecta al país por más de cinco décadas tiene la posibilidad de resolverse por la vía política con las guerrillas que hasta la actualidad mantienen el alzamiento. Los acuerdos conseguidos por el Gobierno nacional y las FARC-EP, insurgencia de mayores raíces históricas, presencia territorial y potencial militar, tiene avances notables en la mayoría de los temas de la agenda y se enfila hacia el 
logro de un acuerdo general y la preparación de un cese general y definitivo de las hostilidades. Entre tanto, Gobierno nacional y ELN, la guerrilla restante, aunque con lentitud, exploran el pronto inicio de otra negociación de paz, que ya se anuncia enfocada a cesar las hostilidades y converger con el otro acuerdo hacia una sinergia que posibilite la construcción de paz en la fase posacuerdos. De tener éxito estos dos pactos de paz, se cerraría el conflicto bélico prolongado por más de cinco décadas, y si se aplican medidas coherentes con una paz sostenible, podrían superarse causas, dinámicas y consecuencias dejadas por la guerra irregular interna.

\section{Referencias}

Canal Capital, noticiero. (2015, 11 de sep.). Entrevista con el comandante del ELN Nicolás Rodríguez. Bogotá, DC.

Centro de Memoria Histórica, Fundación Social, Universidad de los Andes, Unidad para la Atención y Reparación Integral de las Víctimas, OIM. (2012, sep.). Encuesta Nacional ¿Qué piensan los colombianos después de siete años de "justicia y paz"? Bogotá DC.

El Espectador. (2015, 5 de jul). Por bien o por mal el proceso de paz se está acabando. Juan Gossaín, entrevista a Humberto de La Calle. Bogotá, DC.

EI Espectador. (2015, 5 de oct.). Entrevista a Eduardo González, director Programa Verdad y Memoria, ICTJ. Por Jorge Iván Posada. Bogotá, DC.

EI Espectador. (2015, 25 de sept.). Justicia, cárcel y paz. Cesar Rodríguez Garavito. Bogotá, DC.

El Espectador. (2015, 27 de sep.). Justicia imperfecta, paz posible. Rodrigo Uprimny. Bogotá, DC.

El Espectador. (2015, 9 de oct.). Discrepancias de forma y fondo. Declaraciones de Humberto de la Calle, jefe negociador del Gobierno. Bogotá, DC.

EI Espectador. (2015, 11 de sep.). Gobierno dice que refrendará la paz. Declaración del presidente Juan Manuel Santos. Declaración de Rodrigo Uprimny. Bogotá, DC.

El Espectador. (2015, 6 de dic.). Umbral para la paz. Rodrigo Uprimny. Bogotá, DC. 
El Espectador. (2015, 9 de sep.). Declaraciones del ministro del Interior Juan Fernando Cristo. Bogotá, DC.

El Espectador. (2015). Editorial. Cautela para el posconflicto. Bogotá, DC.

El Espectador. (2015, 29 de nov.). En tanto el proceso de paz no exista en fase pública no es viable. Entrevista al comandante Antonio García. Víctor CurreaLugo. Bogotá, DC.

El Espectador. (2015, 8 de julio). Las cuentas del ELN. Víctor de Currea Lugo. Bogotá, DC.

EI Tiempo. (2015, 24 de sep.). Lajurisdicción especial de paz no aplicará para un eventual acuerdo con el ELN. Bogotá DC.

EI Tiempo. (2015, 9 de oct.). Injusticia con los militares. El pecado de ser inocente. Plinio Apuleyo Mendoza. Bogotá, DC.

El Tiempo. (2015, 24 de sep.). Declaraciones de la Fiscal General de la CPI, Fatou Besouda. Declaraciones de José Miguel Vivanco. Bogotá, DC.

EI Tiempo. (2015, 26 de sep.). Comandante del Ejército habla de revisión de la doctrina militar. Bogotá, DC.

El Tiempo. (2015, 1 de nov. ). Lo que falta para llegar al año nuevo sin guerra con las FARC. Marisol Gómez. Bogotá, DC.

Fisas, Vicenc. (2015, octubre). Diplomacias de paz, negociar con grupos armados. Barcelona: Icaria, Más Madera.

Noticiero RCN radio. (2015, 17 de sep.). Declaración de Iván Márquez. La Habana, Cuba. Bogotá, DC.

Revista Semana (2015, sep.). Para la historia. Nueve mentiras, Antonio Caballero. La hora definitiva de Uribe, León Valencia. Guiño global. (1743). Bogotá, DC.

Revista Semana (2015, oct.). ¿Y después del indulto qué? (1752). Bogotá, DC.

Revista Semana (2015, nov.). ¿Dónde están los desacuerdos? (1754). Bogotá, DC. 